\title{
EXPLORING THE USE OF DIGITAL DATA IN THE AGRI-FOOD CONTEXT
}

\author{
Moreno Frau' ${ }^{1}$ (D) \\ Francesca Cabiddu ${ }^{2}$
}

DOI: https://doi.org/10.31410/ITEMA.S.P.2019.117

\begin{abstract}
This paper explores digital data exploitation behaviors and shows how these comportments change according to the data sources employed by the firms when trying to develop their products. This article aims to provide a theoretical framework concerning how digital data are employed for product development. Since the relationship between data exploitation and product development represents an empirically under-explored research area, the authors adopt an exploratory multiple case study design to develop new theoretical and empirical insights pertaining to this topic. This paper provides guidelines that help agri-food firms recognize the features of how food processing might take advantage of digital transformation and digital data gaining competitiveness by improving production efficiency and supporting the development of their products.
\end{abstract}

Keywords: Digitization, Digital Transformation, Food Processing, Product Development, Behavior.

\section{INTRODUCTION}

$\mathrm{D}_{2}$ igital transformation is dramatically changing the face of the economy (Matzler et al. 2018). Digital transformation is the application of new technologies [...] [which] requires skills that involve the extraction and exchange of data as well as the analysis and conversion of that data into actionable information. (Schallmo, Williams, and Boardman 2017, 4). Previous studies on technological innovation and food production (e.g. Beckeman, Bourlakis, and Olsson 2013; Grunert et al. 2008), on one hand, have significantly explained how agri-food firms made use of technologies and what new food products have been developed due to the new technologies (e.g. Leek, Szmigin, and Carrigan 2001; Marette et al. 2009; Steenis and Fischer 2016). On the other hand, they missed the opportunity to investigate the increasing availability of digital data in a poor-technology-adopter sector, and how the information gathered by the elaboration of digital data can foster product development (Schweitzer, Handrich, and Heidenreich 2019). This gap inspires our research question: how do low-tech firms exploit digital data to develop their products?

This article contributes by empirically demonstrating that digital data exploitation behaviors change according to the data sources employed by the firms when trying to develop their products. Our paper is structured as follows: firstly, we argue for the effects of digital transformation and the use of digital technologies in the agri-food industry; secondly, we display the methodology that was adopted to conduct the study; then, we thoroughly discuss the key findings; finally, we conclude with the discussions, research limitations, and some implications for future research.

\footnotetext{
$1 \quad$ Università degli studi di Cagliari, Via Sant'Ignazio da Laconi, 74, 09123, Cagliari, Italy
}

2 Università degli studi di Cagliari, Via Sant'Ignazio da Laconi, 74, 09123, Cagliari, Italy 


\section{DIGITAL TRANSFORMATION IN THE AGRI-FOOD INDUSTRY}

The impact of digital transformation on the agri-food industry is greatly influencing raw materials supply chain, production, processing, distribution, and marketing (Weick 2001). The digital transformation in food production fosters the creation of new types of machinery, such as 3D food printers (Charlebois and Juhasz 2018). Still, the technologies used to produce space food, which is the food of astronauts during the space missions, gives the opportunity to supply healthy ready-to-eat food to busy people on Planet Earth (Varese and Cane 2017). Recently, the adoption of micro and nanotechnologies (Marette et al. 2009; Steenis and Fischer 2016), allowed, for example, the encapsulation of food active components (Roos et al. 2016). As a consequence, firms could introduce in the market a great number of innovative new functional foods (Bigliardi and Galati 2013; Tollin and Erz 2017).

The happening of the digital transformation in the agri-food industry has divided customers into opened versus skeptics towards the adoption of new technologies. Looking at the relationship between consumers' age and product selection, elderly people are usually willing to pay a premium price for products treated with technologies that provide added health benefits (Leek, Szmigin, and Carrigan 2001). Conversely, millennials who care about sustainability issues are skeptic regarding the positive contribution of technologies to produce more sustainable food products and consider dangerous those technologies adopted to prolong food shelf life (Cavaliere and Ventura 2018; Steenis and Fischer 2016). However, a study on consumer preferences for familiar versus novel food products claims that age is not a determinant factor in consumption decisions with familiar products, while it plays a more decisive role in the structure of preference regarding novel food products, particularly in young consumers (Barrenar, García, and Camarena 2015). In the presence of irrational behaviors, customers may contrast new food technologies, this is a phenomenon known as technophobia (Gorgitano, Verneau, and Sodano 2017). To obstruct technophobia and change consumer attitudes toward food technologies adoption, firms need to associate food innovations with positive pictures, which not only has immediate benefits but also prevents positive effects from extinction (Loebnitz and Grunert 2015). Briefly, to launch a successful new food product in the market, it is advocated to involve the customers in the food development process for improving consumers' acceptance (Busse and Siebert 2018).

So far, agri-food research has greatly explained how technologies have been employed by the food industry and what food products have been created by the intensive use of technologies (e.g. Leek, Szmigin, and Carrigan 2001; Marette et al. 2009; Steenis and Fischer 2016). These studies also deeply investigate the role of the customer in the food industry, providing interesting insights regarding the technological centers, suppliers, retailers, and manufacturers too (e.g. Beckeman, Bourlakis, and Olsson 2013; Beckeman and Olsson 2011). Notwithstanding, just a few scholars studied the adoption of new digital technologies and focused on a pivotal phenomenon such as digital transformation in the agri-food firms (Vlachos, 2004; Anastasiadis, Tsolakis and Srai, 2018). Thus, previous research missed the opportunity to study the increasing availability of digital data generated by the application of new technologies in food production, and how the information provided by the processing of digital data can support product development (Schweitzer, Handrich, and Heidenreich 2019). 


\section{METHODOLOGY}

This paper aims to provide a theoretical framework concerning how digital data are employed for product development. Since low-tech firms' digital transformation is an empirically underexplored field of research, we adopt an exploratory multiple case-study design (Eisenhardt and Graebner 2007). We ground the theorizing in the empirical data for an in-depth understanding of the research question.

Data Collection. We collected data from both primary and secondary sources: (a) semi-structured interviews with actors involved in the digital transformation strategy, digital data analysis, and product development process (e.g. CEOs, IT, R\&D and Digital transformation specialists); (b) archival data (e.g. technological improvement and product development plans), company social media pages and websites.

We adopted an interview protocol consisting of 12 questions and several bullet questions divided into three sections: 1) preliminary questions about the company, the interviewee and the context the of phenomenon; 2) questions related to the firm technologies that create digital data; 3) questions concerning how the firm exploit digital data to develop its products. The questions asked of the interviewees included, e.g., what kind of data does food processing machinery create? How does the firm save/store data concerning food processing? Which is the process followed by the company for the development of new products? And, in this process, how useful was the data related to food processing created thanks to the new technologies? The 8 interviews were recorded and transcribed within 24 hours. They lasted from 42 to 58 minutes. We complemented the interviews with the collection of data from firms' social media, websites and internal plans and reports (when made available) in order to triangulate data sources.

Data Analysis. We conducted data analyses in four cumulative stages of coding, starting with the within-case analysis of each case, moving from the specific case context to the overall phenomenon (Saldaña 2015; Eisenhardt and Graebner 2007).

We started with a preliminary within-case analysis of the 8 cases and their individual characteristics by reconstructing the summaries of distinct case studies. During the first coding process, we segmented and grouped data following a data-driven coding scheme. We identified a set of descriptive codes (Miles and Huberman 1994). Accordingly, the outcome of this stage of coding was a list of codes as observed in the single-considered cases.

At the second stage of coding, we began with the abstraction process either categorized new data under existing codes, grouping similar codes or created a new code if it was analytically distinct. Consequently, we reanalyzed the descriptive codes, looking for interpretative codes that reflect the researcher's understanding of the data (Miles and Huberman 1994).

Then, we carried out the third stage of coding which led the analysis to a further level of abstraction. Starting from the previously identified interpretative codes, we looked for patterns (Miles and Huberman 1994). In doing so, we identified two behaviors which, according to our analysis explain how digital data are employed for product development (see Table 1).

The final stage of data analysis involved assessing the relationships among them. This final stage of coding aimed at connecting the constructs and transformed them from static and standalone behaviors into dynamic and integrated theoretical frameworks. 
Table 1: Summary of digital data exploitation behaviors

\begin{tabular}{|l|l|l|}
\hline Phenomenon & Behavior & Illustrative quote \\
\hline $\begin{array}{l}\text { Digital data } \\
\text { exploitation }\end{array}$ & Data receiver & $\begin{array}{l}\text { Then there are a bunch of analyzes of product quality and productivity. We } \\
\text { don't need to do additional analysis. From the data collected by the machin- } \\
\text { ery, the information system generates information for us. Then, the man has } \\
\text { to interpret the information, but we have already available all the analyzes we } \\
\text { need. Managing director, Case study 1. }\end{array}$ \\
\cline { 2 - 3 } & Data explorer & $\begin{array}{l}\text { Machinery suppliers partially limit the autonomy of the company to carry out } \\
\text { independent analyzes. We are a bit forced to use and follow their models. We } \\
\text { are able to carry out independent analyzes thanks to the additional sensors } \\
\text { that we insert in the machinery to produce an autonomous and parallel data } \\
\text { collection. Head of IT \& Digital Transformation, Case study 8. }\end{array}$ \\
\hline
\end{tabular}

\section{DIGITAL DATA EXPLOITATION BEHAVIORS IN LOW-TECH FIRMS}

Firms analyze data for several reasons. Our research focuses on the exploitation of digital data for product development in terms of additional benefits to the customer (incremental innovation) or the creation of new products. Moreover, firms analyze data from different sources. For example, raw materials, production process, warehouse (data internally created) or data related to market trends, partnerships, competitors, sales (data externally created). We combined the types of product development processes with different data sources and found two behaviors connected to digital data exploitation: Data receiver and Data explorer. These two behaviors can also be observed simultaneously in the same firm (Mixed behavior).

Data Receiver. Data receivers have a passive attitude towards data analysis which is mainly done to produce standardize pieces of information to foster product development. The Data receiver is the most common behavior among the firms of this study. According to our analysis, Data receivers conduct analysis on data concerning internal aspects of the firm with the aim of improving current products by exploiting internally created data: Each production is a test, the data are analyzed to identify strengths and weaknesses of the product. Over time, we improve our products, for example, by changing the flour mixture or inserting another type of raw material, said the quality manager of case study 2 . Data receivers also want to improve their current products (or create variations of them) and they do that by performing analysis also on firms' external dynamics (e.g. sales or mark trends): We track everything we sell and we usually invest in products that sell the most to create variations of them. These variations are likely to be accepted by the market explained the IT specialist of case study 3. Lastly, Data receivers are exploiting externally collected data to create new products. For instance, by analyzing competitors' products, as the CEO of case study 6 put it: We are followers as regards the creation of new products. We observe large companies that can make important investments in research and development... then, we analyze their products and we try to adapt to what the largest companies do.

Data Explorer. Such behavior is adopted by firms that explore digital data by examining them with a critical eye and deepening data analysis to find novel pieces of information. Our analysis detected a few numbers of Digital explorers that query their database to create new products and understand whether they are able to do so, as the CEO of case study 7 up it: Production data are analyzed to create new products. Therefore, the opening of new markets is done by analyzing the production data to understand if the production plant is capable of producing a product that presents new characteristics that make the products more interesting to the final customer. For example, it happened when we created the hamburger made of seitan. 
Mixed Behavior. Among the Data explorers and Data receivers, there are firms that conduct both behaviors but in distinct situations. Firms in this group behave as Data receivers when they exploit digital data to make simple or routinized decisions. To do so, Mixed behavior firms use the standard information make available by the information system. On the other hand, when Mixed behavior firms face new problems and have to make not-routinized decisions, they dig into the collected digital data to find information for supporting the diction-making process. Our analysis discloses that Mixed behavior firms are the ones that better exploit their availability of digital data since they exploit internally and externally collected data to perform both incremental innovation and new product development.

\section{CONCLUSION AND FUTURE RESEARCH DIRECTIONS}

Building on prior research on digital transformation and digital technologies in the agri-food industry, our study contributes by providing first insights about how low-tech firms exploit digital data for product development. Our research empirically demonstrates that digital data exploitation behaviors change according to the data sources employed by the firms when trying to develop their products.

Digital data exploitation behaviors and the lack of new product miners. Earlier research clearly identifies digital data as the key outcome of the digital transformation (Dremel et al. 2017). Studies on technological innovation in the food production (e.g. Beckeman, Bourlakis, and Olsson 2013; Grunert et al. 2008), at one end, shed light on how agri-food firms utilize technologies and what new products have been developed due to the new technologies (e.g. Leek, Szmigin, and Carrigan 2001; Marette et al. 2009; Steenis and Fischer 2016). On the other end, they do not investigate the increasing availability of digital data in the agri-food sector, and how the information gathered by the analysis of digital data can affect product development (Schweitzer, Handrich, and Heidenreich 2019). Our study extends previous research by identifying digital data behaviors and theorizing how these behaviors change according to the data source and the kinds of the product development process. More specifically, while previous research demonstrates that new technologies adoption has positive implications in terms of product development, our analysis suggests that firms mostly adopt a passive behavior (Data receiver) when exploiting digital data both for incremental innovation and new product development. Data receiver feed their product development process with the information made available by the information system. However, the results also show that active behavior (Data explorer) is needed to exploit internally created data (e.g., production data) with the intent of creating new products. Despite the importance of exploiting digital data for new product development, Data explores are a minority. They display an active will in finding correlation between their available data and the possibility to create new producers (e.g., verifying whether the production plant is able to produce a new product or not). Finally, when firms are able to behave as Data receiver and Data explorer simultaneously (Mixed behavior), they are also fully exploiting the potential of internal and external data to innovate their current products and/or create new ones.

Future Research. The exploratory design of this research implies limitations that suggest avenues for further theoretical and empirical research. The choice of the agri-food industry and the restriction to food processing firms as the research's empirical setting provides a partial view of the digital transformation in the broader social field of low-tech firms. Additionally, this study was based on a sample of 8 cases within a single geographical market (Italy). Future research is needed to extend our approach to other low-tech sectors (e.g. tourism), particularly 
in a multinational/multicultural context. A plurality of industries and cultures may suggest different behaviors leading to digital data exploitation for product development. Furthermore, our research considers the production firm's point-of-view. Hence, the analysis was based on data from just one actor. However, digital data exploitation also involves several players within the food industry and each one may affect digital data exploitation. Therefore, future research could consider a multi-actor perspective in order to analyze the same phenomena by involving, e.g., software house specialized in developing solutions for agri-food firms, digital data analysts, machinery suppliers.

\section{REFERENCES}

Barrenar, Ramo, Teresa García, \& Dena María Camarena. (2015). 'An Analysis of the Decision Structure for Food Innovation on the Basis of Consumer Age'. International Food and Agribusiness Management Review 18(3): 149-170.

Beckeman, Märit, Michael Bourlakis, \& Annika Olsson. (2013). 'The Role of Manufacturers in Food Innovations in Sweden'. British food journal 115(7): 953-974.

Beckeman, Märit, \& Annika Olsson. (2011). 'The Role of Swedish Retailers in Food Innovations'. The International Review of Retail, Distribution and Consumer Research 21(1): 51-70.

Bigliardi, Barbara, \& Francesco Galati. (2013). 'Innovation Trends in the Food Industry: The Case of Functional Foods'. Trends in Food Science \& Technology 31(2): 118-129.

Busse, Maria, \& Rosemarie Siebert. (2018). 'The Role of Consumers in Food Innovation Processes'. European Journal of Innovation Management 21(1): 20-43.

Cavaliere, Alessia, \& Vera Ventura. (2018). 'Mismatch between Food Sustainability and Consumer Acceptance toward Innovation Technologies among Millennial Students: The Case of Shelf Life Extension'. Journal of Cleaner Production 175: 641-650.

Charlebois, Sylvain, \& Mark Juhasz. (2018). 'Food Futures and 3D Printing: Strategic Market Foresight and the Case of Structur3D'. International Journal on Food System Dynamics 9(2): 138-148.

Dremel, Christian. (2017). 'How AUDI AG Established Big Data Analytics in Its Digital Transformation.' MIS Quarterly Executive 16(2).

Eisenhardt, Kathleen M., \& Melissa E. Graebner. (2007). 'Theory Building from Cases: Opportunities and Challenges'. Academy of management journal 50(1): 25-32.

Gorgitano, Maria Teresa, Fabio Verneau, \& Valeria Sodano. (2017). 'Sustainable Food Innovation Finding the Right Balance between Technological Determinism and Technophobia.' Quality-Access to Success 18.

Grunert, Klaus G. (2008). 'User-Oriented Innovation in the Food Sector: Relevant Streams of Research and an Agenda for Future Work'. Trends in Food Science \& Technology 19(11): 590-602.

Leek, Sheena, Isabelle Szmigin, \& Marylyn Carrigan. (2001). 'Older Consumers and Food Innovation'. Journal of International Food \& Agribusiness Marketing 12(1): 71-89.

Loebnitz, Natascha, \& Klaus G. Grunert. (2015). 'Evaluative Conditioning of Food Technologies'. Psychology \& Marketing 32(7): 725-741.

Marette, Stéphan. (2009). 'Impact of Environmental, Societal and Health Information on Consumers' Choices for Nanofood'. Journal of Agricultural \& Food Industrial Organization $7(2)$.

Matzler, Kurt, Stephan Friedrich von den Eichen, Markus Anschober, \& Thomas Kohler. (2018). 'The Crusade of Digital Disruption'. Journal of Business Strategy 39(6): 13-20. 
Miles, Matthew B., \& A. Michael Huberman. (1994). Qualitative Data Analysis: An Expanded Sourcebook. Sage.

Roos, Yrjö H. (2016). 'Food Engineering at Multiple Scales: Case Studies, Challenges and the Future - a European Perspective'. Food Engineering Reviews 8(2): 91-115.

Saldaña, Johnny. (2015). The Coding Manual for Qualitative Researchers. London: Sage.

Schallmo, Daniel, Christopher A. Williams, \& Luke Boardman. (2017). 'Digital Transformation of Business Models-Best Practice, Enablers, and Roadmap'. International Journal of Innovation Management 21(08): 1740014.

Schweitzer, Fiona Maria, Matthias Handrich, \& Sven Heidenreich. (2019). 'Digital Transformation in the New Product Development Process: The Role of It-Enabled PLM Systems for Relational, Structural, and NPD Performance'. International Journal of Innovation Management: 1950067.

Steenis, Nigel D., \& Arnout RH Fischer. (2016). 'Consumer Attitudes towards Nanotechnology in Food Products: An Attribute-Based Analysis'. British Food Journal 118(5): 1254-1267.

Tollin, Karin, \& Antonia Erz. (2017). 'The Strategic Viewpoints of Innovation and Marketing Teams on the Development of Novel Functional Foods'. In Developing New Functional Food and Nutraceutical Products, Elsevier, 63-83.

Varese, Erica, \& Paola Cane. (2017). 'From Space Food Research and Innovation to Immediate Advantages for Earth Eating Habits: An Aerospace-Food Producer Company Case Study'. British Food Journal 119(11): 2448-2461.

Weick, Cynthia Wagner. (2001). 'Agribusiness Technology in 2010: Directions and Challenges'. Technology in Society 23(1): 59-72. 